\title{
Confirmed or unconfirmed cases of 2019 novel coronavirus pneumonia in Italian patients: a retrospective analysis of clinical features
}

Giulia De Angelis ${ }^{1,2 \dagger}{ }^{+}$Brunella Posteraro ${ }^{1,3+}{ }^{+}$Federico Biscetti ${ }^{3}$, Gianluca laniro ${ }^{3}$, Lorenzo Zileri Dal Verme ${ }^{3}$, Paola Cattani ${ }^{1,2}$, Francesco Franceschi ${ }^{4}$, Maurizio Sanguinetti ${ }^{1,2^{*}}$ (D) and Antonio Gasbarrini ${ }^{3}$

\begin{abstract}
Background: Since December 2019, the severe acute respiratory syndrome coronavirus 2 (SARS-CoV-2) emerged as a novel etiologic agent of viral pneumonia. We aimed to compare clinical features of 165 Italian patients with laboratory confirmed or unconfirmed 2019-nCoV pneumonia.

Methods: On March 31, 2020, hospitalized patients who presented with fever and/or respiratory symptoms, exposures, and presence of lung imaging features consistent with 2019-nCoV pneumonia were included. Before admission to a hospital ward, patients underwent RT-PCR based SARS-CoV-2 RNA detection in their nasopharyngeal swab samples.

Results: Of 165 patients studied, 119 had positive RT-PCR results and 46 were RT-PCR negative for 2 days or longer (i.e., when the last swab sample was obtained). The median age was 70 years (IQR, 58-78), and 123 (74.6\%) of 165 patients had at least one comorbidity. The majority of patients (101/165, 61.2\%) had a mild pneumonia, and the remaining patients (64/ $165,38.8 \%$ ) a severe/critical pneumonia. We did not find any substantial difference in symptoms, incubation periods, and radiographic/ $C T$ abnormalities as well as in many of the biological abnormalities recorded. However, at multivariable analysis, higher concentrations of hemoglobin $(\mathrm{OR}, 1.34 ; 95 \% \mathrm{Cl}, 1.11-1.65 ; P=0.003)$ and lower counts of leukocytes $(\mathrm{OR}, 0.81 ; 95 \%$ $\mathrm{Cl}, 0.72-0.90 ; P<0.001)$ were statistically associated with confirmed COVID-19 diagnosis. While mortality rates were similar, patients with confirmed diagnosis were more likely to receive antivirals ( $95 \%$ vs $19.6 \%, P<0.001)$ and to develop ARDS (63\% vs $37 \%, P=0.003$ ) than those with unconfirmed COVID-19 diagnosis.
\end{abstract}

Conclusions: Our findings suggest that unconfirmed 2019-nCoV pneumonia cases may be actually COVID-19 cases and that clinicians should be cautious when managing patients with presentations compatible with COVID-19.

Keywords: Pneumonia, COVID-19, Clinical and laboratory findings, Outcomes

\footnotetext{
* Correspondence: maurizio.sanguinetti@unicatt.it

${ }^{+}$Giulia De Angelis and Brunella Posteraro contributed equally to this work.

'Dipartimento di Scienze Biotecnologiche di Base, Cliniche Intensivologiche e

Perioperatorie, Università Cattolica del Sacro Cuore, Rome, Italy

${ }^{2}$ Dipartimento di Scienze di Laboratorio e Infettivologiche, Fondazione

Policlinico Universitario A. Gemelli IRCCS, Largo A. Gemelli 8, 00168 Rome,

Italy

Full list of author information is available at the end of the article
}

C The Author(s). 2020 Open Access This article is licensed under a Creative Commons Attribution 4.0 International License, which permits use, sharing, adaptation, distribution and reproduction in any medium or format, as long as you give appropriate credit to the original author(s) and the source, provide a link to the Creative Commons licence, and indicate if changes were made. The images or other third party material in this article are included in the article's Creative Commons licence, unless indicated otherwise in a credit line to the material. If material is not included in the article's Creative Commons licence and your intended use is not permitted by statutory regulation or exceeds the permitted use, you will need to obtain permission directly from the copyright holder. To view a copy of this licence, visit http://creativecommons.org/licenses/by/4.0/ The Creative Commons Public Domain Dedication waiver (http://creativecommons.org/publicdomain/zero/1.0/) applies to the data made available in this article, unless otherwise stated in a credit line to the data. 


\section{Background}

The 2019 novel coronavirus (2019-nCoV), named severe acute respiratory syndrome coronavirus 2 (SARS-CoV2), became notorious since December 2019 as a new etiologic agent of viral pneumonia [1]. In early illness stages, patients with coronavirus disease 2019 (COVID19) present with symptoms of acute respiratory infection, which can progress to acute respiratory distress syndrome (ARDS) and other serious complications [2]. Because of substantial pneumonia-related morbidity and mortality [3], testing for SARS-CoV-2 infection of patients who meet the suspected-case definition for COVID-19 [4] is central for their management. Accordingly, provision of supportive care (e.g., oxygenation, ventilation, and fluid therapy) and/or administration of antiviral agents may be decisive [5].

Real-time reverse-transcriptase-polymerase-chain-reaction (RT-PCR) based SARS-CoV-2 RNA detection in respiratory samples (e.g., nasopharyngeal swabs) is the reference diagnostic method to confirm COVID-19 [6]. However, one or more negative results do not exclude the likelihood of SARS-CoV-2 infection [4]. Currently published studies suggest lung imaging, biomarkers, and other non-microbiological tests as ancillary diagnostic methods [6], encouraging further investigation to understand the value of radiological or laboratory findings to diagnose COVID-19. We comparatively explored the clinical features of 165 patients with laboratory confirmed or unconfirmed 2019-nCoV pneumonia admitted to COVID-19 wards of the Fondazione Policlinico A. Gemelli IRCCS, which is a tertiary care university hospital in Rome, Italy. Thus, we investigated the prospect that cases with a negative RT-PCR test result are actually cases of 2019-nCoV pneumonia or, in other words, are not to distinguish from those without confirmation test performed.

\section{Methods}

This retrospective, single-center observational study was conducted in accordance with the Declaration of Helsinki and was approved by the Ethics Committee of the Fondazione Policlinico A. Gemelli IRCCS (reference number $17057 / 20$ ), and written informed consent was obtained from each enrolled patient. All patients who were hospitalized for suspected 2019-nCoV pneumonia [7] on March 31, 2020 were considered for recruitment. Inclusion criteria were fever and/or respiratory symptoms, exposures, and presence of lung imaging features consistent with 2019-nCoV pneumonia [8]. At the emergency room (before admission to a hospital ward), all patients had undergone nasal and oropharyngeal swabs for detection of one or more SARS-CoV-2 specific nucleic acid targets [9], using the Korean Ministry of Food and Drug Safety approved Allplex 2019-nCoV assay (Arrow Diagnostics S.r.l., Genova, Italy). Samples resulted negative had been repeated after $48-72 \mathrm{~h}$. To rule out the presence of infections due to common viral (adenovirus, coronaviruses 229E, HKU1, NL63, OC43, influenza viruses, rhinovirus/enterovirus, etc.) or bacterial (Bordetella pertussis, Chlamydophila pneumoniae, Legionella pneumophila, Mycoplasma pneumoniae) pathogens, patients' samples had also been tested with the GenMark's ePlex Respiratory Pathogen Panel assay. Eleven patients yielding positive results for the etiological agents above mentioned were not included.

We retrieved demographic, clinical, laboratory, imaging, treatment, and outcome data from the patients' medical chart records. We classified cases as mild (see above specification), severe (i.e., dyspnea, respiratory rate $\geq 30$ breaths $/ \mathrm{min}$, blood oxygen saturation $\leq 93 \%$, and partial pressure of arterial oxygen $\left[\mathrm{PaO}_{2}\right] /$ fraction of inspired oxygen $\left[\mathrm{FiO}_{2}\right] \leq 300 \mathrm{mmHg}$ ), or critical (i.e., respiratory failure, septic shock, and/or multiple organ failure) pneumonia. We recorded chest X-ray or computed tomography (CT) features using the Fleischner Society terminology [10], we defined ARDS based on timing, lung imaging, origin of edema, and oxygenation as specified in the Berlin definition [11], and we defined liver injury as transaminase elevation two- to three-times the upper limit of normal (e.g., $45 \mathrm{U} / \mathrm{L}$ for alanine aminotransferase). According to the Italian Society of Infectious Diseases guidelines for COVID-19 treatment [12], we administered antiviral agents (e.g., lopinavir/ritonavir) to all patients with severe/critical disease or to patients with mild disease who had comorbidities including age $>70$. Categorical variables were expressed as number with percentage and were compared using the $\chi^{2}$ test, and continuous variables were expressed as median with interquartile range (IQR) and were compared using the Mann-Whitney $U$-test. A two-sided $P$ value of $<0.05$ was considered statistically significant. We performed univariate analysis using the aforementioned tests, and all significant variables (among demographics and baseline characteristics) were included in a multivariable logistic regression model to identify those variables that were statistically associated with confirmed COVID-19 diagnosis. Odds ratio (OR) values with 95\% confidence intervals (CIs) were calculated. All analyses were performed with Stata software version 11.1 (StataCorp, College Station, TX, USA).

\section{Results}

On March 31, 2020, 176 patients were hospitalized at our center with a suspicion of 2019-nCoV pneumonia, and 165 patients were finally included. Of them, 119 were confirmed COVID-19 cases based on positive RTPCR results on nasopharyngeal swabs [4], and 46 were RT-PCR negative for 2 days or longer (i.e., when the last swab sample was obtained). 
Table 1 shows demographic and clinical characteristics of 165 patients at baseline. The median age was 70 years (IQR, 58-78), and 113 patients were males. One hundred and twenty-three $(74.6 \%)$ patients had at least one comorbidity. The most common symptoms at admission were fever $(n=155,93.9 \%)$, dyspnea $(n=92,55.8 \%)$ and cough $(n=77,46.7 \%)$, and the median time from symptom onset to COVID-19 diagnosis was 7 days (IQR, 3-10). Overall, lactate dehydrogenase levels (median value, $289 \mathrm{U} / \mathrm{L} ; \mathrm{IQR}$, 230-415) and C-reactive protein levels (median value, 74.0 $\mathrm{mg} / \mathrm{L}$; IQR, 32.2-139.4) were elevated. One hundred and twenty-seven patients (77\%) presented with X-ray signs of ground-glass opacity, and 106 (64.2\%) with signs of consolidation. At admission, $101(61.2 \%)$ presented with a mild pneumonia, and the remaining 64 patients (38.8\%) with a severe/critical pneumonia.

Treatments and outcomes of 165 patients are detailed in Table 1. Overall, 92 patients (55.8\%) developed ARDS, and 14 of them $(8.5 \%)$ septic shock, which needed transfer to ICU. Most patients $(n=128,77.6 \%)$ were treated with oxygen support, antivirals $(n=122,73.9 \%)$, and antibiotics $(n=133,80.6 \%)$. Forty-six patients $(27.9 \%)$ received therapy with interleukin-6 receptor inhibitors. Overall, 16 (9.7\%) of 165 patients died at the follow-up end ( $n=13$ because ARDS, $n=2$ because of septic shock, $n=1$ because of multiple comorbidities).

At univariate analysis, fever was significantly more frequent in patients with confirmed diagnosis $(96.6 \%$ vs $87.0 \%, P=0.02)$. This group presented also with significantly lower levels of leucocytes (median value, $6.0 \times$ $10^{9} / \mathrm{L}$ vs $10.1 \times 10^{9} / \mathrm{L} ; P<0.001$ ), neutrophils (median value, $4.6 \times 10^{9} / \mathrm{L}$ vs $\left.7.7 \times 10^{9} / \mathrm{L} ; \quad P<0.001\right)$, platelets (median value, $203 \times 10^{9} / \mathrm{L}$ vs $250 \times 10^{9} / \mathrm{L} ; P=0.01$ ), and procalcitonin (median value, $0.08 \mathrm{ng} / \mathrm{mL}$ vs $0.15 \mathrm{ng} / \mathrm{mL}$, $P=0.006$ ), and higher levels of hemoglobin (median value, $14.1 \mathrm{~g} / \mathrm{dL}$ vs $12.1 \mathrm{~g} / \mathrm{dL} ; P<0.001)$, alanine aminotransferase (median value, $26 \mathrm{U} / \mathrm{L}$ vs $19 \mathrm{U} / \mathrm{L}, P=0.02$ ), and lactate dehydrogenase (median value, $316 \mathrm{U} / \mathrm{L}$ vs $245 \mathrm{U} / \mathrm{L} ; P<0.001)$. Patients with confirmed diagnosis were also more likely to receive antivirals ( $95 \%$ vs $19.6 \%$, $P<0.001)$ and to develop ARDS (63\% vs $37 \%, P=0.003)$ than those without confirmed diagnosis. There were no other significant differences between the two groups.

At multivariable analysis, higher concentrations of hemoglobin (OR, 1.34; 95\% CI, 1.11-1.65; $P=0.003)$ and lower counts of leukocytes (OR, 0.81; 95\% CI, 0.72-0.90; $P<0.001$ ) were found to be statistically associated with confirmed diagnosis in the overall cohort.

\section{Discussion}

We tested the hypothesis that negative patients did not differ from SARS-CoV-2 RNA positive patients by comparing features of 165 cases with clinically diagnosed 2019-nCoV pneumonia in our hospital. We did not find any substantial difference in symptoms, incubation periods, and radiographic/CT abnormalities as well as in many of the biological abnormalities recorded. However, blood/serum test results showed that patients with laboratory-confirmed diagnosis of 2019-nCoV pneumonia were more likely to have higher levels of hemoglobin and lower levels of leukocytes. Additionally, the proportion of ARDS in the group of COVID-19 confirmed patients was significantly higher than in the group of COVID-19 unconfirmed patients.

Large or small descriptive studies published in 2020 mainly focused on patients with laboratory-confirmed 2019-nCoV pneumonia [2, 13, 14]. Nonetheless, among 72,314 cases (as of February 11, 2020) from the COVID19 outbreak in China, 16,186 (22\%) and 10,567 (15\%) of them could not receive laboratory confirmation for COVID-19 and, then, were classified as suspected cases or clinically diagnosed cases, respectively [8]. Although testing for SARS-CoV-2 in our laboratory was not restricted [15], 46 (27.8\%) of 165 patients with 2019-nCoV pneumonia did not have a laboratory-confirmed diagnosis in our study. Despite a well-documented active virus replication in the upper respiratory tract [16], swab samples may have a limited sensitivity to identify cases. Sampling or testing related factors may be responsible for false-negative RT-PCR results, necessitating additional sample collection from the lower respiratory tract specimens including sputum [4].

It is plausible that our SARS-CoV-2 negative patients were outside the window of peak shedding in the upper respiratory tract samples or did not have symptoms highly suggestive for upper respiratory tract infection [16]. Accordingly, eight of 119 patients with positive RT-PCR results became positive only with swabs taken on subsequent days after the first (negative) sampled swab, and their median time from symptom onset did not differ from that of 111 remaining patients ( 7 days vs 7 days, $P=$ 0.76). Furthermore, the sensitivity of the Allplex 2019$\mathrm{nCoV}$ assay might have limited by its requirement that three genes were all detectable for a positive result. In our study, all 46 patients had a radiological evidence of pneumonia not attributed to any typical respiratory viral infection agents, including the human coronaviruses HKU1, OC43, NL63, 229E, the influenza virus $A$ and $B$, and others (data not shown). It is worthy to note that the finding of typical ground glass opacities in chest CTs of clinically diagnosed patients [17] prompted the Chinese authorities, at one point in early February 2020, to count these patients as confirmed cases [18]. This allowed identifying and quarantining patients as early as possible.

In conclusion, using the clinical diagnosis as the reference standard, the RT-PCR testing allowed to correctly identify two thirds of our patients as COVID-19 while one third was not correctly 
Table 1 Demographics, baseline characteristics, and outcomes of patients diagnosed with 2019-nCoV pneumonia

\begin{tabular}{|c|c|c|c|c|c|}
\hline Variable & $\begin{array}{l}\text { Total } \\
(n=165)\end{array}$ & $\begin{array}{l}\text { Confirmed Diagnosis }{ }^{a} \\
(n=119)\end{array}$ & $\begin{array}{l}\text { Unconfirmed Diagnosis }{ }^{a} \\
(n=46)\end{array}$ & $P$ Value & $\begin{array}{l}\text { OR } \\
(95 \% \mathrm{CI})^{\mathrm{b}}\end{array}$ \\
\hline Age (years), median (IQR) & $70(58-78)$ & $68(58-77)$ & $73.5(58-85)$ & 0.09 & $\ldots$ \\
\hline Male sex & $113(68.5)$ & $85(71.4)$ & $28(60.9)$ & 0.19 & $\ldots$ \\
\hline \multicolumn{6}{|l|}{ Pre-existing conditions } \\
\hline Any & $123(74.6)$ & $86(72.3)$ & $37(80.4)$ & 0.28 & $\ldots$ \\
\hline Cardiovascular disease & $77(46.7)$ & $59(49.6)$ & $18(39.1)$ & 0.23 & $\ldots$ \\
\hline Connective tissue disease & $30(18.2)$ & $23(19.3)$ & $7(15.2)$ & 0.54 & $\ldots$ \\
\hline Nervous system disease & $29(17.6)$ & $18(15.1)$ & $11(23.9)$ & 0.18 & $\cdots$ \\
\hline Diabetes & $22(13.3)$ & $15(12.6)$ & $7(15.2)$ & 0.66 & $\ldots$ \\
\hline Malignancy & $21(12.7)$ & $12(10.1)$ & $9(19.6)$ & 0.10 & $\ldots$ \\
\hline Respiratory system disease & $18(10.9)$ & $12(10.1)$ & $6(13.0)$ & 0.59 & $\ldots$ \\
\hline Chronic kidney disease & $15(9.1)$ & $8(6.7)$ & $7(15.2)$ & 0.09 & $\ldots$ \\
\hline Immunodeficiency & $7(4.2)$ & $3(2.5)$ & $4(8.7)$ & 0.08 & $\ldots$ \\
\hline Chronic liver disease & $3(1.8)$ & $3(2.5)$ & $0(0.0)$ & 0.28 & $\ldots$ \\
\hline Other ${ }^{c}$ & $29(17.6)$ & $17(14.3)$ & $12(26.1)$ & 0.07 & $\ldots$ \\
\hline \multicolumn{6}{|l|}{ Symptoms at admission } \\
\hline Fever & $155(93.9)$ & $115(96.6)$ & $40(87.0)$ & 0.02 & $\ldots$ \\
\hline Shortness of breath (or dyspnea) & $92(55.8)$ & $63(52.9)$ & $29(63.0)$ & 0.24 & $\ldots$ \\
\hline Cough & $77(46.7)$ & $60(50.4)$ & $17(37.0)$ & 0.12 & $\ldots$ \\
\hline Diarrhea/Nausea/Nomiting & $6(3.6)$ & $3(2.5)$ & $3(6.5)$ & 0.22 & $\ldots$ \\
\hline Days from symptom onset, median (IQR) & $7(3-10)$ & $7(3-10)$ & $7(3-10)$ & 0.41 & $\ldots$ \\
\hline \multicolumn{6}{|l|}{ Signs at admission, median (IQR) } \\
\hline Heart rate (beats/min) & $89(80-101)$ & $89(80-102)$ & $92(80-100)$ & 0.99 & $\ldots$ \\
\hline Respiration rate (breaths/min) & $14(12-15)$ & $14(12-16)$ & $13(12-15)$ & 0.24 & $\ldots$ \\
\hline Blood oxygen saturation (\%) & $94(90-96)$ & $94(90-96)$ & $93(90-97)$ & 0.74 & $\ldots$ \\
\hline Systolic blood pressure (mmHg) & $\begin{array}{l}130(120- \\
140)\end{array}$ & $130(120-140)$ & $130(118-140)$ & 0.97 & $\ldots$ \\
\hline Diastolic blood pressure (mmHg) & $80(70-86)$ & $80(70-86)$ & $75(66-88)$ & 0.56 & $\ldots$ \\
\hline qSOFA score $(\geq 2)$ & $25(15.2)$ & $17(14.3)$ & $8(17.4)$ & 0.62 & $\ldots$ \\
\hline \multicolumn{6}{|l|}{ Chest $\mathrm{X}$-ray/CT findings } \\
\hline Ground-glass opacity (GGO) & $127(77.0)$ & $96(80.7)$ & $31(67.4)$ & 0.07 & $\ldots$ \\
\hline Consolidation & $106(64.2)$ & $79(66.4)$ & $27(58.7)$ & 0.35 & $\ldots$ \\
\hline Pleural effusion & $40(24.2)$ & $24(20.2)$ & $16(34.8)$ & 0.19 & $\ldots$ \\
\hline \multicolumn{6}{|l|}{$C T$ findings only ${ }^{d}$} \\
\hline GGO and reticular & $\begin{array}{l}29 / 112 \\
(17.6)\end{array}$ & 21/76 (17.6) & $8 / 36(17.4)$ & 0.54 & $\ldots$ \\
\hline Pleural thickening/retraction & $6 / 112(3.6)$ & $3 / 76(2.5)$ & $3 / 36(6.5)$ & 0.34 & $\ldots$ \\
\hline Fibrotic steaks & $5 / 112(3.0)$ & $3 / 76(2.5)$ & $2 / 36(4.3)$ & 0.70 & $\ldots$ \\
\hline Air bronchogram & $3 / 112(1.8)$ & 2/76 (1.7) & $1 / 36(2.2)$ & 0.96 & $\ldots$ \\
\hline Bronchus distortion & $2 / 112(1.2)$ & $2 / 76(1.7)$ & $0 / 36(0.0)$ & 0.33 & $\ldots$ \\
\hline \multicolumn{6}{|l|}{ Spectrum of disease } \\
\hline Mild & $101(61.2)$ & $72(60.5)$ & $29(63.0)$ & 0.76 & $\ldots$ \\
\hline Severe & $53(32.1)$ & $39(32.8)$ & $14(30.4)$ & 0.77 & $\ldots$ \\
\hline Critical & $11(6.7)$ & $8(6.7)$ & $3(6.5)$ & 0.96 & $\ldots$ \\
\hline
\end{tabular}

Blood parameters, median (IQR) 
Table 1 Demographics, baseline characteristics, and outcomes of patients diagnosed with 2019-nCoV pneumonia (Continued)

\begin{tabular}{|c|c|c|c|c|c|}
\hline Variable & $\begin{array}{l}\text { Total } \\
(n=165)\end{array}$ & $\begin{array}{l}\text { Confirmed Diagnosis }{ }^{a} \\
(n=119)\end{array}$ & $\begin{array}{l}\text { Unconfirmed Diagnosis }{ }^{a} \\
(n=46)\end{array}$ & $P$ Value & $\begin{array}{l}\text { OR } \\
(95 \% \mathrm{Cl})^{\mathrm{b}}\end{array}$ \\
\hline Leucocytes ( $\times 10^{9} / L ;$ normal range $\left.4.0-10.0\right)$ & $6.4(4.8-9.7)$ & $6.0(4.7-8.1)$ & $10.1(6.1-15.4)$ & $<0.001$ & $0.81(0.72-0.90)$ \\
\hline Neutrophils (×109/L; normal range $2.0-7.0$ ) & $4.9(3.5-7.7)$ & $4.6(3.3-6.3)$ & $7.7(4.6-11.7)$ & $<0.001$ & $\cdots$ \\
\hline $\begin{array}{l}\text { Lymphocytes } \\
\left(\times 10^{9} / L ; \text { normal range } 1.0-3.0\right)\end{array}$ & $1.1(0.8-1.4)$ & $1.1(0.8-1.4)$ & $1.2(0.7-1.6)$ & 0.78 & $\cdots$ \\
\hline Neutrophils (\%) & $\begin{array}{l}77.1 \\
(69.5-82.8)\end{array}$ & $76.3(67.6-82.4)$ & $80.1(71.9-87.3)$ & 0.03 & $\cdots$ \\
\hline Lymphocytes (\%) & $\begin{array}{l}15.8 \\
(10.5-23.4)\end{array}$ & $17.6(12.5-24.3)$ & $12.1(7.6-20.4)$ & 0.003 & $\cdots$ \\
\hline Platelets $\left(\times 10^{9} / \mathrm{L}\right.$; normal range $\left.150-450\right)$ & $\begin{array}{l}210 \\
(169-264)\end{array}$ & $203(165-252)$ & $250(189-301)$ & 0.01 & $\cdots$ \\
\hline Hemoglobin (g/dL; normal range 13-17) & $\begin{array}{l}13.8 \\
(12.1-14.9)\end{array}$ & $14.1(13.0-15.1)$ & $12.1(10.6-14.1)$ & $<0.001$ & $1.34(1.11-1.65)$ \\
\hline \multicolumn{6}{|l|}{ Serum parameters, median (IQR) } \\
\hline $\begin{array}{l}\text { Alanine aminotransferase }(U / L \text {; normal range } \\
7-45)\end{array}$ & $24(16-39)$ & $26(17-40)$ & $19(13-33)$ & 0.02 & $\ldots$ \\
\hline $\begin{array}{l}\text { Lactate dehydrogenase } \\
(\mathrm{U} / \mathrm{L} \text {; normal range } 120-250)\end{array}$ & $\begin{array}{l}289 \\
(230-415)\end{array}$ & $316(254-433)$ & $245(195-336)$ & $<0.001$ & $1.00(0.99-1.01)$ \\
\hline Creatinine (mg/dL; normal range: $0.7-1.1)$ & $0.9(0.8-1.3)$ & $0.9(0.8-1.3)$ & $1.0(0.8-1.3)$ & 0.59 & $\ldots$ \\
\hline Creatine kinase (U/L; normal range 30-170) & $\begin{array}{l}120 \\
(66-219)\end{array}$ & $122(72-218)$ & $107(51-219)$ & 0.36 & $\cdots$ \\
\hline Urea (mg/dL; normal range 10-23) & $17(14-26)$ & $17(13-25)$ & $19(15-32)$ & 0.32 & $\ldots$ \\
\hline \multicolumn{6}{|l|}{ Infection-related biomarkers, median (IQR) } \\
\hline Procalcitonin (ng/mL; normal range $0-0.5$ ) & $\begin{array}{l}0.09 \\
(0.04-0.18)\end{array}$ & $0.08(0.04-0.15)$ & $0.15(0.07-0.63)$ & 0.006 & $\ldots$ \\
\hline $\begin{array}{l}\text { C-reactive protein } \\
\text { (mg/L; normal range } 0-5.0)\end{array}$ & $\begin{array}{l}74.0 \\
(32.2-139.4)\end{array}$ & $66.9(33.6-130.5)$ & $93.6(22.1-163.9)$ & 0.59 & $\ldots$ \\
\hline \multicolumn{6}{|l|}{ Complications } \\
\hline Acute respiratory distress syndrome & $92(55.8)$ & $75(63.0)$ & $17(37.0)$ & 0.003 & $\ldots^{e}$ \\
\hline Liver injury & $47(28.5)$ & $38(31.9)$ & $9(19.6)$ & 0.11 & $\ldots^{e}$ \\
\hline Septic shock & $14(8.5)$ & $7(5.9)$ & $7(15.2)$ & 0.06 & $\ldots^{\mathrm{e}}$ \\
\hline Admission to intensive care unit & $14(8.5)$ & $12(10.1)$ & $2(4.4)$ & 0.23 & $\ldots^{e}$ \\
\hline \multicolumn{6}{|l|}{ Treatment } \\
\hline Oxygen support (nasal cannula) & $128(77.6)$ & $98(82.4)$ & $30(65.2)$ & 0.02 & $\ldots^{e}$ \\
\hline Antiviral therapy & $122(73.9)$ & $113(95.0)$ & $9(19.6)$ & $<0.001$ & $\ldots^{e}$ \\
\hline Antibiotic therapy & $133(80.6)$ & $93(78.2)$ & $40(87.0)$ & 0.20 & $\ldots^{\mathrm{e}}$ \\
\hline Interleukin-6 receptor inhibitor therapy & $46(27.9)$ & $45(37.8)$ & $1(2.2)$ & $<0.001$ & $\ldots^{e}$ \\
\hline \multicolumn{6}{|l|}{ Outcome } \\
\hline Discharged & $125(75.8)$ & $88(74.0)$ & $37(80.4)$ & 0.38 & $\ldots^{e}$ \\
\hline Still in hospital as of $4 / 23 / 2020^{f}$ & $24(14.6)$ & $20(16.8)$ & $4(8.7)$ & 0.18 & $\ldots^{e}$ \\
\hline Died & $16(9.7)$ & $11(9.2)$ & $5(10.9)$ & 0.75 & $\ldots^{e}$ \\
\hline
\end{tabular}

Data are no. (\%) unless specified otherwise. Denominators indicate data lacking for 53 patients. Abbreviations: OR, Odds ratio; $\mathrm{Cl}$, confidence interval; IQR, interquartile range; qSOFA, quick sepsis-related organ failure assessment; $\mathrm{CT}$, computed tomography

a Laboratory-based confirmation of 2019-nCoV pneumonia was done by SARS-CoV-2 RNA detection using a well-established RT-PCR assay [9]

${ }^{\mathrm{b}}$ According to multivariable logistic regression model analysis (see text for details)

c Includes anemia, endocrine disorders, inflammatory bowel disease, and obesity

${ }^{d} \mathrm{CT}$ findings in all 112 patients were assessed according to imaging features described elsewhere [10]

${ }^{\mathrm{e}}$ Not calculated because the relative variable was not entered into multivariable logistic regression model (see text for details)

fPatients were admitted between $3 / 6 / 2020$ and 3/31/2020, with follow-up through 4/23/2020 
identified. However, as undocumented SARS-CoV-2 infections may be a relevant source of transmission among hospitalized patients [19], we believe that clinicians should exceed on the side of caution when managing patients with presentations compatible with COVID-19.

\section{Abbreviations}

2019-nCoV: 2019 novel coronavirus; SARS-CoV-2: Severe acute respiratory syndrome coronavirus 2; COVID-19: Coronavirus disease 2019; ARDS: Acute respiratory distress syndrome; RT-PCR: Reverse-transcriptase-polymerasechain-reaction; $\mathrm{PaO}_{2}$ : Partial pressure of arterial oxygen; $\mathrm{FiO}_{2}$ : Fraction of inspired oxygen; CT: Computed tomography; IQR: Interquartile range; OR: Odds ratio; Cl: Confidence interval; ICU: Intensive care unit

\section{Acknowledgments}

The authors are grateful to Franziska Lohmeyer PhD for her English language assistance and to clinical staff members for collection of samples.

\section{Authors' contributions}

GDA, BP, MS, and AG conceived and designed the study. GDA, FB, GI, LZDV acquired, analyzed, and interpreted the data. GDA and FB performed statistical analyses. BP, MS, and AG supervised the work. BP was the major contributor in writing the manuscript. PC and FF critically revised the manuscript for important intellectual concept. All authors read and approved the final manuscript.

\section{Funding}

The Reale Group and the Fondazione Valentino Garavani \& Giancarlo Giammetti, to support the COVID-19 Research in our Institution, financed this work. The funders had no role in the design and conduct of the study; collection, management, analysis, and interpretation of the data; preparation, review, or approval of the manuscript; and decision to submit the manuscript for publication.

\section{Availability of data and materials}

The datasets generated and analyzed during the current study are not publicly available as the data also forms part of an ongoing study but are available from the corresponding author on reasonable request.

\section{Ethics approval and consent to participate}

This retrospective, single-center observational study was conducted in accordance with the Declaration of Helsinki and was approved by the Ethics Committee of the Fondazione Policlinico A. Gemelli IRCCS (reference number 17057/20), and written informed consent was obtained from each patient.

\section{Consent for publication}

Not applicable.

\section{Competing interests}

The authors declare that they have no competing interests.

\section{Author details}

'Dipartimento di Scienze Biotecnologiche di Base, Cliniche Intensivologiche e Perioperatorie, Università Cattolica del Sacro Cuore, Rome, Italy. ${ }^{2}$ Dipartimento di Scienze di Laboratorio e Infettivologiche, Fondazione Policlinico Universitario A. Gemelli IRCCS, Largo A. Gemelli 8, 00168 Rome, Italy. ${ }^{3}$ Dipartimento di Scienze Mediche e Chirurgiche, Fondazione Policlinico Universitario A. Gemelli IRCCS, Rome, Italy. ${ }^{4}$ Dipartimento di Scienze dell'Emergenza, Anestesiologiche e della Rianimazione, Fondazione Policlinico Universitario A. Gemelli IRCCS, Rome, Italy.

Received: 14 June 2020 Accepted: 12 October 2020

Published online: 19 October 2020

\section{References}

1. Zhu N, Zhang D, Wang W, et al. A novel coronavirus from patients with pneumonia in China, 2019. N Engl J Med. 2020;382:727-33.

2. Huang C, Wang Y, Li X, et al. Clinical features of patients infected with 2019 novel coronavirus in Wuhan, China. Lancet. 2020;395:497-506.
3. Lai CC, Wang CY, Wang YH, Hsueh SC, Ko WC, Hsueh PR. Global epidemiology of coronavirus disease 2019 (COVID-19): disease incidence, daily cumulative index, mortality, and their association with country healthcare resources and economic status. Int J Antimicrob Agents. 2020;55: 105946.

4. WHO. Laboratory testing for coronavirus disease (COVID-19) in suspected human cases. In: Interim guidance. Geneva: World Health Organization; 2020. Available at: https://apps.who.int/iris/bitstream/handle/10665/331501/ WHO-COVID-19-laboratory-2020.5-eng.pdf? sequence=1\&isAllowed=y. Accessed 26 Apr 2020.

5. Cunningham AC, Goh HP, Koh D. Treatment of COVID-19: old tricks for new challenges. Crit Care. 2020;24:91.

6. Cheng MP, Papenburg J, Desjardins M, et al. Diagnostic testing for severe acute respiratory syndrome-related coronavirus-2: a narrative review. Ann Intern Med. 2020;172:726-34.

7. WHO. Global surveillance for COVID-19 caused by human infection with COVID-19 virus. In: Interim guidance. Geneva: World Health Organization; 2020. Available at: https://www.who.int/docs/default-source/coronaviruse/2 020-03-20-surveillance.pdf?sfvrsn=e6be6ef1_2. Accessed 26 Apr 2020.

8. Wu Z, McGoogan JM. Characteristics of and important lessons from the coronavirus disease 2019 (COVID-19) outbreak in China: summary of a report of 72314 cases from the Chinese Center for Disease Control and Prevention. JAMA. 2020;323:1239-42.

9. Corman VM, Landt O, Kaiser M, et al. Detection of 2019 novel coronavirus (2019-nCoV) by real-time RT-PCR. Euro Surveill. 2020;25:2000045.

10. Hansell DM, Bankier AA, MacMahon H, McLoud TC, Müller NL, Remy J. Fleischner society: glossary of terms for thoracic imaging. Radiology. 2008; 246:697-722.

11. Definition Task Force ARDS, Ranieri VM, Rubenfeld GD, et al. Acute respiratory distress syndrome: the Berlin Definition. JAMA. 2012;307:2526-33.

12. Società Italiana di Malattie Infettive e Tropicali. Vademecum per la cura delle persone con malattia da COVI-19. Version 2.0 (in Italian). Available at: www. simit.org/medias/1569-covid19-vademecum-13-03-202.pdf. Accessed 26 April 2020.

13. Chen N, Zhou M, Dong X, et al. Epidemiological and clinical characteristics of 99 cases of 2019 novel coronavirus pneumonia in Wuhan, China: a descriptive study. Lancet. 2020:395:507-13.

14. Grasselli G, Zangrillo A, Zanella A, et al. Baseline characteristics and outcomes of 1591 patients infected with SARS-CoV-2 admitted to ICUs of the Lombardy region, Italy. JAMA. 2020;323:1574-81.

15. Posteraro B, Marchetti S, Romano L, et al. FPG COVID laboratory group. Clinical microbiology laboratory adaptation to COVID-19 emergency: experience at a large teaching hospital in Rome, Italy. Clin Microbiol Infect. 2020;26:1109-11.

16. Wölfel R, Corman VM, Guggemos W, et al. Virological assessment of hospitalized patients with COVID-2019. Nature. 2020;581:465-9.

17. Ai T, Yang Z, Hou H, et al. Correlation of chest CT and RT-PCR testing in coronavirus disease 2019 (COVID-19) in China: a report of 1014 cases. Radiology. 2020;296:E32-40.

18. Yuen KS, Ye ZW, Fung SY, Chan CP, Jin DY. SARS-CoV-2 and COVID-19: the most important research questions. Cell Biosci. 2020;10:40.

19. Li R, Pei S, Chen B, et al. Substantial undocumented infection facilitates the rapid dissemination of novel coronavirus (SARS-CoV2). Science. 2020;368: 489-93.

\section{Publisher's Note}

Springer Nature remains neutral with regard to jurisdictional claims in published maps and institutional affiliations. 